\title{
Introduction of a New Software Package in Teaching Design Methodology for Material Selection
}

\author{
A. Pramanik and M. N. Islam
}

\begin{abstract}
Material selection is an integral part of engineering design. As such, this topic is included in most advanced engineering design units in the Bachelor of Mechanical Engineering. However, students often find this topic difficult and confusing due to the lack of overall knowledge required for the task. This paper describes the introduction of a new software package in a design methodology unit for material selection that provides additional knowledge and hands-on experience to students, which can be applied in their professional lives. The software package introduced three forms of education delivery: lecture, tutorial, and assignment activities. It was found that the introduction of the CES EduPack software package for material and process selection significantly improved students' learning.
\end{abstract}

Index Terms-Design methodology, CES Edupack software, material selection.

\section{INTRODUCTION}

Evidence-based practice is necessary for all students to be successful within their grade level or content specialization [1]. Students need to meaningfully engage in learning activities through interaction with others and meaningful tasks for efficient learning [2]. New technology/software for creating physical understanding permits easier and better concept map construction. This facilitates learning, knowledge capture, and local or distance creation and sharing of structured knowledge [3]. By concentrating on problem solving with several specific media students can engage personally and socially [4]. This paper introduces CES Edupack software in the unit: Design Methodology 431 to improve students' understanding in selecting materials in design.

Design Methodology 431 was introduced as an optional unit for the Bachelor of Mechanical Engineering course at Curtin University in Australia in 2007. Since its commencement, many students have been attracted to this unit because of its practical applications, excellent unit structure, and good unit coordination. This unit helps students to become more familiar with the concept of design. Additionally, it encourages them to develop and apply the concepts in their professional lives. The content of this unit includes a wide range of topics: stages of engineering design, engineering design specifications, quality function deployment, generating conceptual alternatives, function-first decomposition, brainstorming, evaluation and

Manuscript received August 13, 2013; revised November 7, 2013.

The authors are with the Department of Mechanical Engineering, Curtin University, WA, Australia (e-mail: alokesh.pramanik@curtin.edu.au, m.n.islam@curtin.edu.au). redesign of engineering concepts, selecting materials and processes, configuration design of parts, parametric design, optimization methods (including search methods), linear programming, the simplex algorithm, geometric programming, the Taguchi method, robust design, and axiomatic design [5].

The content was divided into 10 lectures. The first lecture, Introduction, presented a general overview, design strategies including concurrent engineering, design for manufacture, design for environment, stages of engineering design, guided iteration methodology, codes and standards, and tolerance considerations. The second lecture, Formulating the Problem, discussed customer requirements, the Kano model of customer satisfaction, quality function deployment (QFD), a QFD example (a car door design), engineering design specifications (EDS), and an EDS example (a portable wind chill meter). The third lecture, Concept Generation and Evaluation, covered two main topics: generating conceptual design alternatives (function-first decomposition, searching via alternative physical laws and effects, applied techniques for creative idea generation, and searching for information) and evaluation and redesign of engineering concepts (Pugh's method, the Dominic method, quality function deployment, and the Pahl and Beitz method. The fourth lecture, Material Selection and Configuration Design of Parts, discussed the material-first approach, process-first approach, hierarchical organization of material alternatives, application issues in selecting materials, Ashby charts, goal of configuration design, and formulation of part configuration problems. The fifth lecture, Parametric Design and Single Variable Optimization Methods, talked about mathematical formation, geometric visualization, optimization by differential calculus, Lagrange multipliers, and different search methods. The six lecture, Multi-variable Optimization Methods, presented multi-variable search methods (lattice search, univariate search, and steepest ascent), linear programming (graphical approach and analytical approach), and the simplex algorithm. The seventh lecture, Taguchi Methods, described methods for parametric design, Taguchi methods (main concepts, meaning of quality, Taguchi's quality loss model, and improving quality), design of experiments (DOE), signal-to-noise ratio, and quality through design. The eighth lecture, Geometric Programming, presented geometric programming (theoretical background, history of GP applications, solution procedure, and solved examples), Johnson's method of optimum design, and multi-factor objective functions. The ninth lecture, Axiomatic Design, talked about the benefits of axiomatic design, the state of current design, the axiomatic design framework, the first axiom (the independence axiom), the second axiom (the information axiom), and the comparison of axiomatic design 
with other methodologies. The tenth lecture, Design Creativity, provided examples of creativity in simple products.

The learning activities used in this unit are lectures, tutorials, assignments, and a group design project. The broad aims of this elective unit are to: 1) permit the student to undertake the study of a specialized subject chosen in preparation for their individual career aspirations; 2) take the student to a higher level of technical knowledge and skills in the area; and 3) allow the student to develop more advanced learning skills that include the demonstration of self-reliance and personal responsibility. The technical aims that are specific to this unit are to provide students with the ability to: 1) understand the stages of engineering design for mechanical systems and devices and to choose tools appropriate for each stage with the aim of optimizing the design process; 2) apply classical design optimization methods (such as linear programming, the simplex algorithm, and geometric programming); and 3) apply modern design methodologies (such as parametric design, robust design, and axiomatic design).

Proper selection of materials is an important part of the engineering design process, as it controls the cost, manufacturing process, and performance of the products. Material types depend on the applications. Each application has its own material requirements, and the materials must work together. Advanced materials, such as, titanium, composites, etc. are expensive but provide better performance.

The demands of product requirements change with time, which affects the design and application of materials. Perhaps the most dramatic example of the ways in which material usage has changed is found in airframes. Early planes were made of low-density woods (spruce, balsa, and ply), steel wire, and silk. Wood remained the principal structural material of airframes well into the twentieth century. However, as planes became larger, it became less and less practical. The aluminum airframe, exemplified by the Douglas DC3, was the answer. It provided the high bending stiffness and strength at a low weight that was necessary for scale-up and extended range. Aluminum remained the dominant structural material of civil airliners for the remainder of the twentieth century. By the end of the century, the pressure for greater fuel economy and lower carbon emissions had reached a level that made composites an increasingly attractive choice, despite their higher cost and greater technical challenge. The future of airframes is exemplified by Boeing's 787 Dreamliner $(80 \%$ carbon-fiber-reinforced plastic by volume), which is claimed to be $30 \%$ lighter per seat than competing aircraft. Competitive design requires the innovative use of new materials and the clever exploitation of their special properties, both engineering and aesthetic. Many manufacturers of kettles, cleaners, and cameras have failed to innovate and exploit such materials, resulting in their extinction.

Typically, the materials of engineering applications are classified into six broad families: metals, polymers, elastomers, ceramics, glasses, and hybrids [6]. The members of a family have certain features in common, including similar properties and similar processing routes. Often, they also have similar applications. For example, metals are stiff and have relatively high elastic moduli. Ceramics also have high moduli, but unlike metal, they are brittle. Glasses, akin to ceramics, are hard, brittle, and vulnerable to stress. Polymers are at the other end of the spectrum. They have moduli that are low, roughly 50 times lower than those of metals are. However, they can be nearly as strong as metals. Elastomers have Young's moduli as low as $10^{-3} \mathrm{GPa}\left(10^{5}\right.$ times less than that typical of metals) and it increase with temperature (all other solids show a decrease) and have enormous elastic extension. Hybrids are combinations of two or more materials in a predetermined configuration and scale. They combine the attractive properties of the families of materials while avoiding some of their drawbacks.

All materials are defined by their attributes, including density, strength, cost, and resistance to corrosion. A design demands a certain profile of these: a low density, a high strength, a modest cost, and resistance to sea water, perhaps. Design problems are usually open-ended. They do not have a unique or "correct" solution, though some solutions will clearly be better than others are. Thus, the first tool that a designer needs is an open mind, a willingness to consider all possibilities. However, this wide net draws many possibilities. Thus, a procedure is necessary through which to select the excellent from the good. Selecting materials involves seeking the best match between design requirements and the properties of the materials that might be used to make the design. There are 50,000-80,000 materials available, and new materials being continuously developed. It is important to start with the full menu of materials during selection, as failure to do so may mean a missed opportunity. Thus, it is important to identify the desired attribute profile of all materials and then compare this with those of real engineering materials to find the best match.

\section{Procedure of Material SElection}

Selecting materials involves seeking the best match between design requirements and the properties of the materials that might be used to make the design. There are four stages in this process, which are described below [6].

\section{A. Translation}

The design requirements, which are often vague, must first be converted into constraints and objectives that can be applied to the materials database, including supporting a load, containing a pressure, or transmitting heat. Thus, it is important to identify the requirements that the material must meet and express those as constraints and objectives. The constraints are the inability of certain materials to perform certain tasks. This might involved certain dimensions that are fixed or a component needing to carry particular design loads or pressures without failure. Screening out materials that fail to meet these specifications delivers a list of viable candidates. The list is then ranked by required objective properties. In products, there are some preferable attributes that we want to increase as much as possible to add value to the product within the given constrains. The increasing of those desirable attributes is known as objectives. For 
example, this might include making a part as cheaply, light, or safe as possible. Finally, defining the free variables that the designer is free to adjust to optimize the objective can occur. This might include varying dimensions that have not been constrained by design requirements.

\section{B. Screening}

Screening eliminates candidates that cannot do the job at all because one or more of their attributes lies outside the limits set by the constraints. If, for example, the design imposes limits on materials of $E>10 \mathrm{GPa}$ and $\rho<3,000 \mathrm{~kg} / \mathrm{m}^{3}$, then the materials do not fulfill these conditions must be screened out from further consideration.

\section{Ranking}

Ranking measure how well a candidate material can perform that has passed the screening step. It is necessary to arrange the viable materials according to the value of a material index, which is the property or property group that maximizes performance for a given design.

\section{Documentation}

Documentation provides a detailed profile of each candidate. What secret vices might it have? What are its strengths and weaknesses? Does it have a good reputation? What, in a phrase, is its credit rating? The documentation may be descriptive, graphical, or pictorial, which provides case studies of previous uses of the material, failure analyses, details about corrosion, and information about availability and pricing. This step narrows the short-list to a final choice, allowing a definitive match to be made between design requirements and material attributes.

\section{THE SOFTWARE}

As already mentioned, 50,000-80,000 materials are available, and new materials are being developed continuously. As a result, the material selection process involves screening, ranking, and documentation of huge number of materials. Thus, it is not an easy to select materials manually for a certain application. It is also not adequate to offer a good perception in material selection in a traditional way. Thus, the material selection software package, CES EduPack, was introduced in this unit to facilitate students' learning. Essentially, this software package is a huge database of all the available materials. These materials can be arranged, chosen, compared, and calculated using this software package. A typical application of this software package is shown in Fig. 1 and Fig. 2. In Fig. 1 Young's modulus $\mathrm{E}$ is plotted against the density $p$ on $\log$ scales. Each material class occupies a characteristic field. The contours show the longitudinal elastic wave speed $v=(E / p)^{1 / 2}$. Fig. 2 shows the three types of selection windows. They can be used in any order and in any combination. The selection engine isolates the subset of materials that passes all the selection stages.

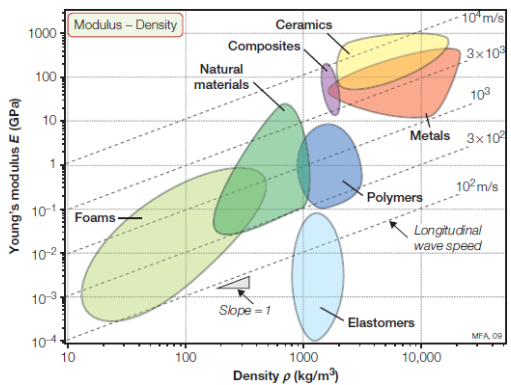

Fig. 1. The idea of material property chart [7].

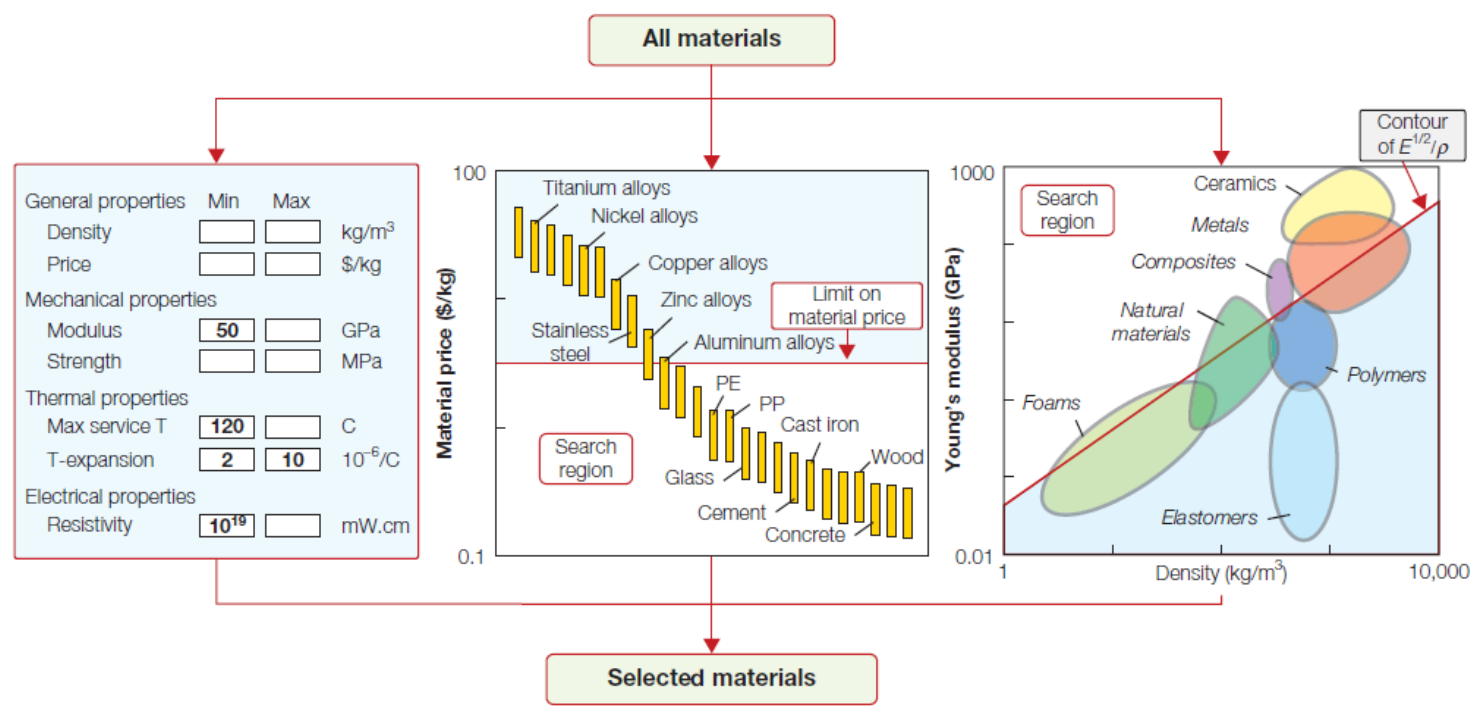

Fig. 2. Computer-aided selection using the CES software package [7].

In addition to the lectures on material selection, a tutorial demonstrated the capability of this software package. Students participated actively in the tutorial class. This gave them a reasonable understanding of the software. Then students were given an assignment to answer by applying the CES EduPack software [7]:

1) Use a "Limit" stage to find materials with modulus $E>1 \# \# \mathrm{GPa}$ and price $C_{m}<\$ 2+\# / \mathrm{kg}$. (The units and currency can be changed in the options menu.)

2) Use a "Limit" stage to find materials with modulus $E>2$ $\mathrm{GPa}$, density $<10 \# \# \mathrm{~kg} / \mathrm{m}^{3}$, and price $C_{m}<\$ 3+\# / \mathrm{kg}$.

3) The speed of longitudinal waves in a material is proportional to $E / \rho$. Plot contours of this quantity onto a copy of an $E-\rho$ chart to allow you to read the approximate values for any material on the chart. Which metals have about the same sound velocity as steel? 
Does sound move faster in titanium or glass?

4) Do titanium alloys have a higher or lower specific strength (strength/density) than the best steels? This is important when you want strength at low weight (landing gear of aircraft, mountain bikes). Use a chart to decide.

5) Is the fracture toughness, $K_{1 c}$, of the common polymers polycarbonate $\mathrm{ABS}$ or polystyrene larger or smaller than the engineering ceramic alumina, $\mathrm{Al}_{2} \mathrm{O}_{3}$ ? Is the toughness the common polymers polycarbonate $\mathrm{ABS}$ or polystyrene larger or smaller than that of engineering ceramic alumina? Use a graph of $K_{1 c}-E$.

6) Use the fracture toughness-modulus chart to find materials that have fracture toughness that exceeds $1 \# \#$ $\mathrm{MPa} \cdot \mathrm{m}^{1 / 2}$ and $1 \# \mathrm{~kJ} / \mathrm{m}^{2}$.

7) Consider a tie rod with length $L$ defined. It must carry a prescribed tensile load $\mathrm{F}$ without failure (a constraint) while simultaneously being as light as possible (an objective). The area that the force acts on is A. It must not elongate more than $\delta$ under load F. Find out the material index when the goal is to minimize the mass. What are the three best performing materials by this index? Calculate the mass of the tie rod for each material when the bar length=8\#\# $\mathrm{mm}$ and the diameter $=1 \# \# \mathrm{~mm}$.

There are two variables introduced in the questions, such as \# and \#\#, where '\#' is the last digit of the student number and '\#\#' is the last two digits of the student number. These were introduced to prevent students from copying from each other.

\section{IMPROVEMENTS IN LEARNING}

The students' feedbacks clearly indicated that several aspects of learning improved after introducing this software. The comparison of students' feedbacks before and after introducing the CES EduPack software package is given in Table I. The table shows that the number of students increased who agree that learning experiences, learning resources, workload, and quality of teaching have improved in their favor. The most improvement was seen in the learning experiences $(29 \%)$. This indicates that the software package facilitated students' learning by providing a hands-on experience with a useful software package that can be applied in their engineering profession. The number of students who felt that the quality of teaching helped their learning was increased by $22 \%$. This increase was due to incorporating the software package appropriately in this unit. Though the number of overall satisfied students did not increase much (only 7\%), this does suggest favorable improvement in the teaching and learning of the design methodology unit.

TABLE I: STUDENTS’ AGREEMENT WITH DIFFERENT LEARNING ASPECTS BEFORE AND AFTER INTRODUCING THE CES EDUPACK SOFTWARE

\begin{tabular}{|l|c|c|c|}
\hline \multicolumn{1}{|c|}{ Aspects of learning } & Before introducing software, $\%$ & $\begin{array}{c}\text { After introducing } \\
\text { software, } \%\end{array}$ & 93 \\
\hline $\begin{array}{l}\text { The learning experiences in this unit helped } \\
\text { me to achieve the learning outcomes. }\end{array}$ & 64 & 87 & 29 \\
\hline $\begin{array}{l}\text { The learning resources in this unit help me } \\
\text { to achieve the learning outcomes. }\end{array}$ & 86 & 93 & 1 \\
\hline $\begin{array}{l}\text { The workload in this unit is appropriate to } \\
\text { the achievement of the learning outcomes. }\end{array}$ & 86 & 93 & 7 \\
\hline $\begin{array}{l}\text { The quality of teaching in this unit helps me } \\
\text { to achieve the learning outcomes. }\end{array}$ & 86 & 93 & 22 \\
\hline Overall, I am satisfied with this unit. & & & 7 \\
\hline
\end{tabular}

\section{CONCLUSION}

Every student wants to learn. This learning can be improved by additional teaching tools. A practical based teaching tool, such as, CES Edupack is extremely important in professional engineering. It is always exciting for students to have hands on experience in academic courses that can be utilized in their professions. It is clear that students enjoyed the CES EduPack and that it improved their learning. It helped them to better perceive and understand how to select materials according to their needs.

\section{REFERENCES}

[1] D. H. Jonassen, J. Howland, J. Moore, and R. M. Marra, Learning to Solve Problems with Technology: A Constructivist Perspective, 2002.

[2] M. T. Brownell, P. T. Sindelar, M, Kiely, and L. Danielson, "Special education teacher quality and preparation: Exposing foundations, constructing a new model," Exceptional Children, vol. 76, pp. 357-378. 2010 .

[3] J. D. Novak, "The promise of new ideas and new technology for improving teaching and learning," Cell Biology Education, vol. 2, no. 2 pp. 122-132, 2003.

[4] G. Kearsley and B. Shneiderman, "Engagement Theory: A Framework for Technology-Based Teaching and Learning," Educational Technology, vol. 38, no. 5, pp. 20-23, 1998.
[5] M. F. Ashby, "Materials selection in mechanical design," MRS Bulletin, vol. 30, pp. 995, 2005.

[6] G. E. Dieter and L. C. Schmidt, Engineering Design, 4th Ed., McGraw-Hill, 2009

[7] Information on website. (August 8, 2013). [Online]. Available: http://handbook.curtin.edu.au/units/31/310659.html

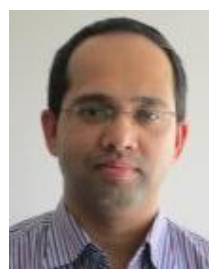

A. Pramanik received the first degree in mechanical engineering from Bangladesh University of Engineering and Technology, Bangladesh. Then he completed Master and $\mathrm{PhD}$ degrees from National University of Singapore, Singapore and the University of Sydney, Australia respectively in Mechanical Engineering. Currently, he is working as a lecturer in Mechanical Engineering at Curtin University, WA, Australia.

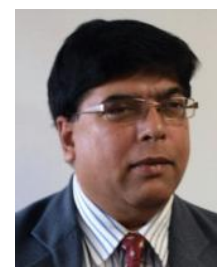

M. N. Islam obtained his first degree in engineering (a combined bachelor's and master's degree in Mechanical Engineering) from the Technical University of Varna, Bulgaria. He obtained his M.E. (Hons) in Mechanical Engineering from the University of Wollongong, Australia and his $\mathrm{PhD}$ in Mechanical and Manufacturing Engineering from the University New South Wales, Australia. Currently, he is working as a senior lecturer at the Department of Mechanical Engineering, Curtin University, Australia. 